\title{
A Study on Mediated Effects to Employability of Undergraduates in Different Groups: Job Intension and Extracurricular Activities
}

\author{
Yang Hongbo, Ma Yutong*, Hu Ping, He Guoshen \\ School of Management \\ Xi'an Jiaotong University \\ Xi'an, China \\ myt19951023@163.com
}

\begin{abstract}
This study explored the factors affecting the employability of college students and compared the difference on the mediator effects of job intension and extracurricular activities between normal colleges and non-normal colleges. Collecting with 3317 students in 5 representative Chinese universities, we find that, 1) Job intension, extracurricular activities and employment services have significant influence on the employability of undergraduates; 2) Job intension and extracurricular activities significantly mediate the relationships between undergraduates' employability and its influencing factors; 3) The mediator effects mentioned above are different between normal colleges and non-normal colleges: Firstly, for normal undergraduates, job intension plays the negative effects on the relationships between education background and employability. However, it does not happen on non-normal undergraduates. Secondly, the mediator effects of extracurricular activities in non-normal undergraduates are greater than that in normal undergraduates.
\end{abstract}

Keywords-Employability; Job intension; Extracurricular activities; Normal colleges; SEM

\section{INTRODUCTION}

With the transition from elite to mass education in China, the number of graduates has been gradually increasing, which reached 6.99 million in 2016 and rose to 7.27 million in 2017 . This triggers several problems confusing the government, which have also been deeply concerned by academic circles. Such as the employment squeeze, the structural contradiction in labor markets and so on. The widely accepted definition of employability is: the ability to get and maintain work, given by American Council on Education.(Chen, 2012) ${ }^{[1]}$ As for the elements of employability, Hillage and Pollard (1998) ${ }^{[2]}$ argued that it consisted of four dimensions: employment assets, expressive ability, planning ability and environment. Bennett et.al(1999) ${ }^{[3]}$ found that it contained specialized knowledge, general and professional skills, as well as occupational consciousness and history. Yorke and Knight (2004) ${ }^{[4]}$ proposed USEM Model to develop the interpretation on elements of employability, while Dacre Pool and Sewell $(2007)^{[5]}$ held Career EDGE Model. Ruth (2009) ${ }^{[6]}$ regarded employability as the combination of personality, general and professional skills, self-management skills and career development. As we can see it, there are a variety of similarities among the interpretation on elements of employability, given by different scholars. While, as Harvey $(2001)^{\text {[7] }}$ put it, employability was not just reflected from some indicators given by a certain institution. Thus, based on the previous theories, this article seeks to construct a more complete system on elements of employability.

Focusing the factors that influence employability, $\mathrm{Xu}(2015)^{[8]}$ analyzed them from two aspects: individual factors and external factors. Nurita et.al (2010) ${ }^{[9]}$ referred these factors as education, training, practice and work experience, and working hours. David et.al (2013) ${ }^{[10]}$ argued that five factors contributed to employability, including soft skills, problem-solving capacity, practical skills, experience and academic reputation. Besides, Erik et.al(2006) $)^{[11]}$ found that human capital of job seekers would have a significant impact on employability, as well as segmentation of primary markets and the prosperity of markets. Further, on the subjective aspects, Washington(1999) ${ }^{[12]}$ found job seekers' self-efficacy could promote their employability. Similarly, we can also find such conclusion in Zhao(2014)'s study ${ }^{[14]}$. Zeng(2010) ${ }^{[13]}$ claimed that both job hunter's attitude towards employment and their self-image also played an important role. In general, there are relatively few studies on the impact of job-seekers' subjective attitudes on employability, particularly concerning subjective aspects as mediators that influence the relationships between other factors and employability.

Currently, increasing study focus on the comparison on students' employment situation and their employability between normal and non-normal colleges. By summarizing related articles, we classify employment feature of students from normal colleges into three points: lacking for enthusiasm of grassroots-level employment, being narrow-minded and working in a relatively concentrated industry.(Zeng et.al, $2014)^{[15]}$ Next, there are a number of comparative literature on factors influencing employability among normal and non-normal colleges. Wang et.al(2010) ${ }^{[16]}$ studied differences in employment preparation between students from different major by independent sample $\mathrm{T}$ test, using the data obtained from 20 colleges in China. They found that science students spent more time in receiving employment service compared to liberal art students, having more adequate preparation and better employment competitiveness. Zhuang(2013) $)^{[17]}$ used 
Informal Learning Theory as a support for analyzing extracurricular activities' forms, as well as functions and influence on students. The data was collected from 6624 students in 27 normal universities. She claimed that their participation frequency of academic research and part-time tutoring had a significantly positive impact on willingness to work as a teacher. Besides, in normal colleges, art students preferred to organize extracurricular activities than science students, which boys also preferred than girls. As for employability including interpersonal skills and practicing ability, science and male students did better than art and female undergraduates. Compared to the later two articles, we can find a number of similarities in the influence of gender and major on employability and participating extracurricular activities between normal and non-normal colleges. Meanwhile, we also find some differences such as art undergraduates are willing to have extracurricular activities than science students in normal colleges, but it is not happened in non-normal colleges. The present studies make a lot of sense. However, there is lack of systematical comparison on differences of employability's model between two groups of samples - normal and non-normal undergraduates. That is, how different between two groups on the path that a bunch of factors influence employability? This article attempts to answer this question.

Based on previous work, we refined the model of employability, especially focusing on the comparison between the normal and non-normal colleges' undergraduates and exploring the differences of employability's model between these two groups. We choose three aspects to describe employability: professional skills, interpersonal skills and information acquisition skill. While, we classify the factors of employability into four dimensions: Job intension, employment service, extracurricular activities and personal characteristics. Next, based on the theories discussed above, we propose hypotheses: Some of have been much studied will be verified here again $(\mathrm{H} 1-\mathrm{H} 4)$. And we put emphasis on exploring the other one which never been studied before (H5).

\section{HYPOTHESIS}

Yang et.al.(2017) ${ }^{[18]}$ claimed that employment service had a positive impact on undergraduates' interpersonal skills and information acquisition skills. However, it had a negative effect on their professional skills since students might not put enough effort into fostering such skills when they received too much employment service. $\operatorname{Liu}(2012)^{[19]}$ found that undergraduates' participating in and organizing activities in colleges would contribute to their employability. Similarly, Yang et.al.(2017) ${ }^{[18]}$ also argued that participating extracurricular activities, as a key factor to interpersonal skills, has a positive effect on undergraduates' employability. As far as job intension, Liu(2010) $)^{[20]}$ found that graduates from the top schools tended to find a job in line with their specialty compared to peers, thus acquiring external benefits. It was because that they possessed higher human capital and they were more competent to jobs in their field than others. Accordingly, we put forward hypotheses one: H1(a): Employment service has a positive effect on undergraduates' employability. H1(b): Participating in extracurricular activities has a positive effect on undergraduates' employability. H1(c): Job seekers

\section{preferring extrinsic reward have higher empl oyability.}

Further, Yang et.al.(2017) ${ }^{[18]}$ found that undergraduates having more employment service might focus on skill training, thus spending less time on extracurricular activities. What's more, receiving more service had a positive impact on job intension because they got a deeper understanding of employment's purpose. This leads us to hypotheses: H2: Having more employment service will lower the frequency of taking part in extracurricular activities. H3: Employment service has a positive effect on undergraduates' job intension.

Personal characteristics in this study are control variables. Eivis et.al.(2014) ${ }^{[21]}$ argued that undergraduates' personality and their major during their colleges played an important role in employability. The following hypotheses were formulated: H4(a): Personal characteristics have an significant impact on undergraduates' employability. H4(b): Personal characterizes have an significant impact on undergraduates' job intension. H4(c): Personal characteristics have significantly impact on undergraduates' participating extracurricular activities.

Huang et.al.(2014) ${ }^{[22]}$ claimed that both undergraduates' general self-efficacy and self-esteem had positive impacts on employability, based on career EDGE Model. What' more, self-esteem played the partially positive mediating role in the relationships of self-efficacy and employability. Wang et.al.(2016) ${ }^{[23]}$ used SEM to find that career decision-making self-efficacy had a complete mediating effect in the relationships between job intension and employability. Ye(2017) ${ }^{[24]}$ made a survey of 802 undergraduates in 5 colleges and argued that the career calling had a positive effect on employability, while job searching self-efficacy and clarity both mediated this effect. Further, viewing from different majors, science students had better job searching clarity and higher employability than art students. And they tended to promote their employability through the better job searching clarity. Besides, Yang et.al.(2017) ${ }^{18]}$ found that job intension and extracurricular activities had partially mediating effects in the relationships of employability and the influencing factors such as gender and major. In general, there are a great many articles about the multiple mediating roles in the model of employability. However, few articles focus on those in different college groups. Among the only articles researching in a specific group, Zhang(2016) ${ }^{[25]}$ found that career exploration had partially mediating effects between self-efficacy and employability, based on the survey of 582 nursing undergraduates. In turn, self-efficacy also had positive mediating effects between career exploration and employability. The nursing students, most of whom are girls, have narrow employment opportunities and are hard to change their majors in China. These also happen in normal type students, which enlighten our article.

On the one hand, the present researches have confirmed job intension, extracurricular activities and employability have a difference in diverse genders and majors. Further, it is also testified that job intension and extracurricular activities have a changing impact on employability rely on different genders and majors. However, previous researches have not studied 
whether this impact is different between normal and non-normal undergraduates. We know whether undergraduates belong to a normal type or not has a correlation with genders and majors, because most of normal undergraduates are girls and study liberty and art. Therefore, we raise a question that: Do job intension and extracurricular activities have a different impact on employability between normal and non-normal undergraduates? On the other hand, we know that job intension and extracurricular activities play mediating roles on the relationships between other factors and employability. Combined with that, we extend the question raised above: Do these mediating effects still exist in both normal and non-normal groups of students? And if so, do these effects differ in different groups? Thus, we make the following hypotheses: H5: job intension has different mediating effects on the relationships between personal characteristics (or employment service) and employability in normal and non-normal undergraduates. H6: Extracurricular activities have changing mediating effects on the relationships between personal characteristics (or employment service) and employability in normal and non-normal undergraduates.

\section{METHOD}

\section{A. Sample}

According to the principle of "representativeness", "differences" and "accessibility of resources", we chose as the research object undergraduates and postgraduates from 5 colleges including Xi'an Jiaotong University, Xi'an University of P\&T, Henan University of Economics and Law, Hangzhou Normal University and Hangzhou Dianzi University. When designing the questionnaire, our research group minimized using of terminology so as to ensure respondents understand the questions correctly, at the same time, avoiding the repetition of the questions. First, the paper questionnaires, as a preliminary research, were sent to students in Xi'an Jiaotong University. Then, our group refined some of questions and started the formal online research. After that, we summarized samples and deleted the default values. Finally, 3307 samples were retained after washing and screening, including 1669 normal college students and 1638 non-normal college students. According to the descriptive statistics, we found that: 1) From gender aspects, the number of girls in normal colleges was about 2 times more than that of boys. While in non-normal colleges, the gender ratio is close to $1: 1.2$ ) From the degree of education, most of samples were undergraduates in both two groups: Undergraduates accounted for $99 \%$ in normal colleges and nearly $70 \%$ in non-normal colleges. 3) From the aspect of major, art students were nearly twice as many as other majors' students in normal colleges. Instead, in non-normal colleges, the number of art students and other majors' was roughly equal.

\section{B. Variable Measures}

TABLE I. shows measure indicators and measure methods among study variables.

Four Latent Variables: Firstly, the variable "Employability" includes 3 secondary variables whose reliability and validity were tested by confirmatory factor analysis (CFA). The results showed that the KMO values of "Professional skills", "Interpersonal skills" and "Information Acquisition skills” were followed by $0.714,0.656$ and 0.638 , while the result of Bartlett test was significant. Besides, the cumulative variance contribution rates were as followed: $60.00 \%, 59.89 \%, 60.42 \%$ and the factor loading were all about $0.7,0.6$ and 0.6 , respectively. Moreover, the standardized Cronbach's Alpha coefficients were followed by 0.662, 0.665 and 0.671 . These indicated 3 secondary variables were all suited to reducing solution. Further, the ETA ${ }^{2}$ demonstrated that the variable "Gender" was significantly related to both "Professional skills" and "Information acquisition skills". "Major" was significantly related to all three variables. "Education" was significantly related to "Professional skills" and "Interpersonal skills". While, "The member of the Communist Party" was only related to "Professional skills". Secondly, the variable "Job intension" includes 3 indicators. Using CFA - the KMO values was 0.686 and the result of Bartlett test was significant, the cumulative variance contribution rate was $69.76 \%$ and the factor loading was beyond 0.6. And the standardized Cronbach's Alpha coefficient was 0.660. After standardizing the factor scores and using Pearson correlative test, we founded that "Job intension" was significantly related to both "Interpersonal skills" and "Information acquisition skills" $(\mathrm{p}=0.01)$. Thirdly, the variable "Professional service" includes 3 indicators. By CFA showing that the KMO values was 0.692 and the result of Bartlett test was significant, the cumulative variance contribution rate was $68.80 \%$ and the factor loading was more than 0.64. The standardized Cronbach's Alpha coefficient was 0.773. Moreover, the results of Pearson correlative test indicated that there was a significant correlation between "Professional service" and "Professional skills \& Information acquisition skills”( $p=0.01)$. Finally, "Extracurricular activities" also includes 3 indicators. Similarly, using CFA - the KMO values was 0.735 and the result of Bartlett test was significant, the cumulative variance contribution rate was $73.74 \%$ and the factor loading was above 0.76 . The standardized Cronbach's Alpha coefficient was 0.873. We founded that "Extracurricular activities" was significantly related to all three secondary variables of "Employability" through Pearson correlative test $(\mathrm{p}=0.01)$. 
TABLE I. MEASUREMENT OF VARIABLES

\begin{tabular}{|c|c|c|c|c|c|c|}
\hline \multicolumn{2}{|c|}{ Variables } & Indicators & \multirow{4}{*}{$\begin{array}{l}\text { Measure Methods } \\
\text { (1) Extremely } \\
\text { dissatisfied } \\
\text { (2) Less satisfied } \\
\text { (3) Not sure } \\
\text { (4) Quite satisfied } \\
\text { (5)Extremely satisfied }\end{array}$} & Variables & Indicators & Measure Methods \\
\hline \multirow{3}{*}{ Employability } & $\begin{array}{l}\text { Professional } \\
\text { skills }\end{array}$ & $\begin{array}{l}\text { (1) Internship } \\
\text { (2) Problem-solving } \\
\text { ability (3) Practice } \\
\text { (4) Application ability }\end{array}$ & & \multirow{3}{*}{$\begin{array}{l}\text { Extracurricular } \\
\text { activities }\end{array}$} & $\begin{array}{l}\text { Club } \\
\text { activities }\end{array}$ & \multirow[t]{3}{*}{$\begin{array}{l}\text { Using the questionnaire } \\
\text { code: } 0-5 \text { shows the } \\
\text { frequency from low to high } \\
\text { level. }\end{array}$} \\
\hline & $\begin{array}{l}\text { Interpersonal } \\
\text { skills }\end{array}$ & $\begin{array}{l}\text { (1) Leadership skills } \\
\text { (2) Communication } \\
\text { skills } \\
\text { (3) Relationship } \\
\text { management ability }\end{array}$ & & & $\begin{array}{l}\text { Part-time } \\
\text { activities }\end{array}$ & \\
\hline & $\begin{array}{l}\text { Information } \\
\text { acquisition } \\
\text { skills }\end{array}$ & $\begin{array}{l}\text { (1)Quantity } \\
\text { (2)Searching time } \\
\text { (3)Quality }\end{array}$ & & & $\begin{array}{l}\text { Learning } \\
\text { activities }\end{array}$ & \\
\hline \multirow{3}{*}{\multicolumn{2}{|c|}{ Job intension }} & Career Preference & (1) Inner meet (2) & \multirow{6}{*}{$\begin{array}{c}\text { Personal } \\
\text { characteristics }\end{array}$} & Gender & (1)Male (0)Female \\
\hline & & Job nature & $\begin{array}{l}\text { Partial inner meet (3) } \\
\text { Neutral (4) Partial } \\
\text { external meet } \\
\text { (5) External meet }\end{array}$ & & Major & $\begin{array}{l}\text { (0)Liberty art(1)Science\& } \\
\text { Economics }\end{array}$ \\
\hline & & Employment area & $\begin{array}{l}\text { (1) Original residence } \\
\text { (2) Big cities } \\
\text { (3) Medium-sized } \\
\text { cities } \\
\text { (4)Wherever as long } \\
\text { as you are satisfied. }\end{array}$ & & $\begin{array}{l}\text { The } \\
\text { member of } \\
\text { the } \\
\text { Communis } \\
\text { t Party }\end{array}$ & (1)Yes (0)No \\
\hline \multirow{3}{*}{\multicolumn{2}{|c|}{ Employment service }} & Career training & \multirow{3}{*}{$\begin{array}{l}\text { (1)Every day (2)Every } \\
\text { week (3)Every month } \\
\text { (4)Every three months } \\
\text { (5)Every six months } \\
\text { and above }\end{array}$} & & \multirow[t]{3}{*}{ Education } & \multirow[t]{3}{*}{$\begin{array}{l}\text { (0)Undergraduate(1)Master } \\
\text { (2) } \mathrm{PhD}\end{array}$} \\
\hline & & Teacher guide & & & & \\
\hline & & Friends guide & & & & \\
\hline
\end{tabular}

\section{ANALYSIS AND DisCUSSION}

\section{A. Regression Analysis on Job Intension, Extracurricular Activities and Employability}

We used OLS to test five models. In Model 1, the dependent variable is Job intension. The dependent variable in Model 2 is extracurricular activities. Three latent variables of employability-Professional skills, Interpersonal skills and Information acquisition skills are the dependent variables in Model 3-5, respectively. All five models have passed F test at the 0.01 level, indicating good fit of theoretical model. Only significant results are shown below. In Model 1, $\operatorname{Gender}\left(\beta=4.80^{* * *}\right)$ and Education $\left(\beta=2.537^{* *}\right)$ all have a significantly positive impact on Job intension. It shows that with other conditions unchanged, men tend to strive for a externally satisfied job compared with women. While people with higher education prefer an externally satisfied job. Thus, $\mathrm{H} 4$ has been partially confirmed while $\mathrm{H} 2$ has not been confirmed. In Model 2, Employment service $\left(\beta=-0.074^{* * *}\right)$ has a negative impact on extracurricular activities. That means the more undergraduates received employment service, the more their participating in extracurricular activities. Besides, $\operatorname{Gender}\left(\beta=-3.494^{* * *}\right)$ and Major $\left(\beta=1.272^{*}\right)$ have significant impact on extracurricular activities, demonstrating that female and science \& economics undergraduates have relatively higher participation than counterparts. Accordingly, H3 was confirmed and $\mathrm{H} 4$ was partially confirmed. In Model 3, Major $\left(\beta=0.623^{*}\right)$ and The Communist Party's member $\left(\beta=-1.274^{* *}\right)$ significantly influence Professional skills, showing the undergraduate who is not a party member and who studies science has a better professional skills. At the same time, Employment service $\left(\beta=-0.038^{* * *}\right)$ and extracurricular activities $\left(\beta=0.839^{* * *}\right)$ also have significant impact on Professional skills, implying that undergraduates have less employment service and more social activities will do better in professional skills. In Model 4, the results show that Job intension $\left(\beta=0.072^{* * *}\right)$, Employment service $\left(\beta=0.039^{*}\right)$ and extracurricular activities $\left(\beta=0.061^{* * *}\right)$ have significant impact on Interpersonal skills. It also happens in Education $\left(\beta=-12.461^{* * *}\right)$ and The Communist Party's member $\left(\beta=5.295^{* * *}\right)$. In Model 5, we have found that Gender $\left(\beta=2.008^{* * *}\right), \quad$ Education $\left(\beta=4.159^{* * *}\right)$, The Communist Party's member $\left(\beta=4.512^{* * *}\right), \quad$ Employment service $\left(\beta=0.164^{* * *}\right)$ and Job intension $\left(\beta=0.031^{* *}\right)$ all have significant and positive effects on Information acquisition skills. This shows that male party members with higher education are more skilled in seeking out information related hunting for a job, compared to their counterparts. In addition, students who want relatively externally satisfied jobs have higher information acquisition abilities. This will be more likely to happen when students prefer social activities. Thus, $\mathrm{H} 1$ and $\mathrm{H} 4$ have been partially confirmed. (Note: ${ }^{* * *} \mathrm{p}<0.01$, $\left.{ }^{* *} \mathrm{p}<0.05,{ }^{*} \mathrm{p}<0.1\right)$

\section{B. Mediated Effects of Job Intension and Extracurricular Activities to Employability in Different Groups}

The two variables-Job intension and extracurricular activities may play the mediating roles at the same time. And the special location of these two variables determines that it is the parallel multiple mediation model. If we use one whole model, the estimated mediating effects of two variables may interfere with each other. Therefore, we used two modelsJob intension and extracurricular activities mediation models - to analyze in this section. 


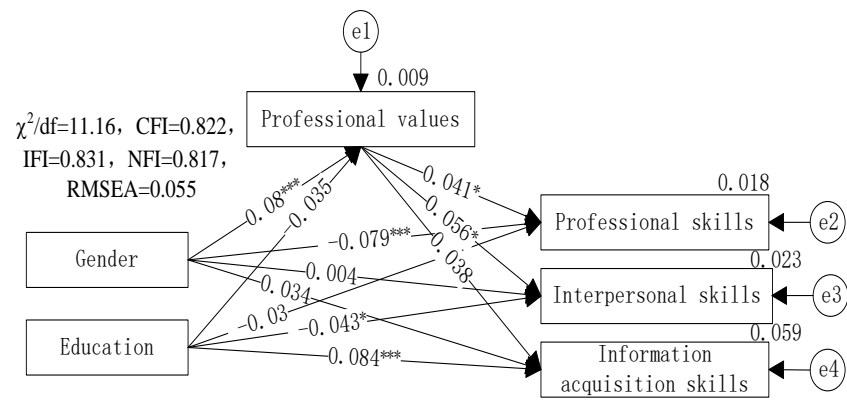

Fig. 1. Mediating effects of Job intension in normal colleges: Standardized parameter estimates

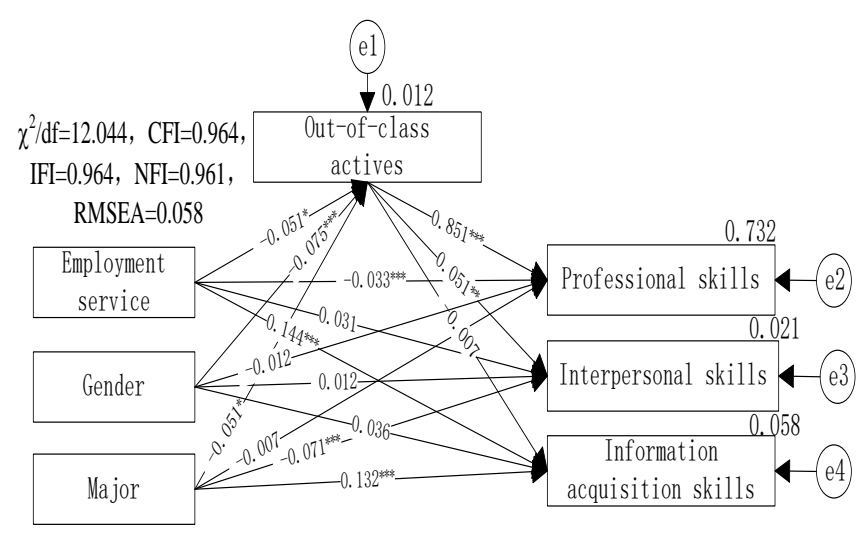

Fig. 3. Mediating effects of extracurricular activities in normal colleges: Standardized parameter estimates

Mediating effects of Job intension: Using SEM, the model fitting is pretty good: we can see goodness of overall fit from Fig.1. Then, we adopt the mediating effects test by Wen et.al.(2005) ${ }^{[27]}$ to obtain direct, mediating and total effects on Employability in two groups. Here, we list and analyze all the significant results. In the sample of normal undergraduates, the variable Job intension plays a significant partial mediating role in the relationship between Gender and Professional skills and it accounts for $4.32 \%$ of the total effect. While Job intension also plays a significant partial mediating role in the relationship between Education and Interpersonal skills, which accounts for $4.36 \%$ of the total effect. Besides, the model's standardized path parameters are shown in Fig.1. In the sample of non-normal undergraduates, we find that Job intension only has a significant partial mediating effect in the relationship between Gender and Professional skills by Wen's test, representing $9.76 \%$ of the total effect. The model's standardized path parameters are shown in Fig.2. Mediating effects of extracurricular activities: The Fig. 3 shows that the model exhibits a good fit. In the sample of normal undergraduates, the model's standardized path parameters are shown in Fig.3. Using Wen's test, we see that extracurricular activities plays a significant partial mediating role in the relationship between Employment service and Professional skills, which accounts for $56.36 \%$ of the total effect. Moreover, there exists the masking effect in the mediating role of extracurricular activities on the relationship between employment service and Interpersonal skills. The Sobel test's results show that extracurricular activities play a significant partial mediating role in that relationship, which

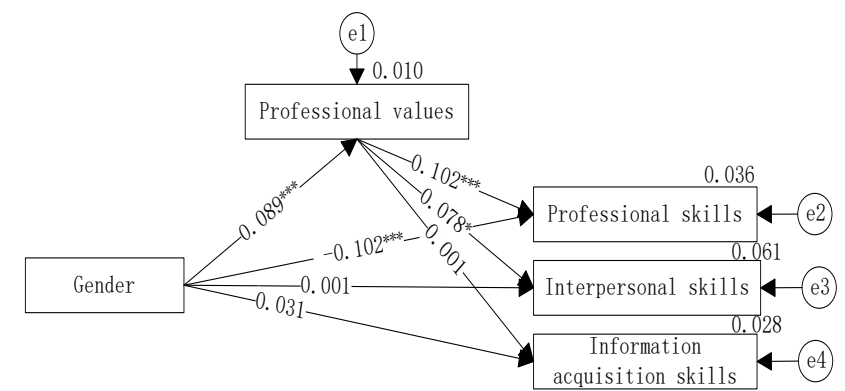

Fig. 2. Mediating effects of Job intension in non-normal colleges: Standardized parameter estimates

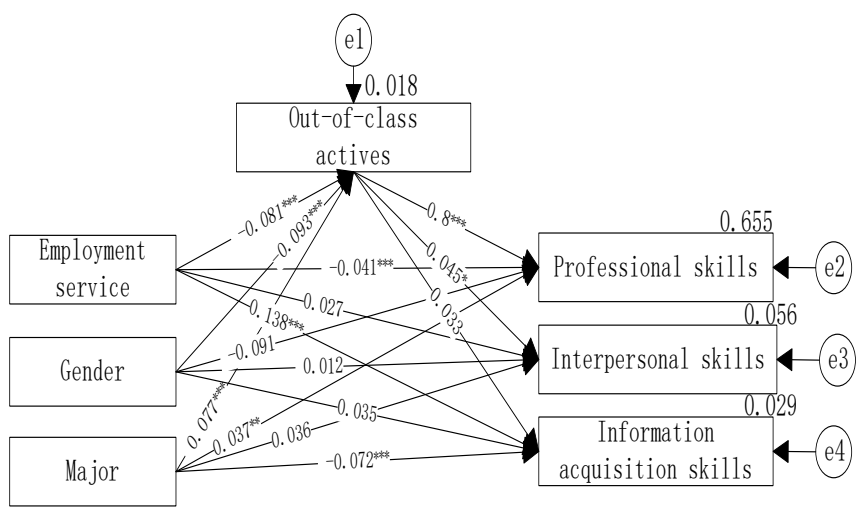

Fig. 4. Mediating effects of ext racurricular activities in non-normal colleges: Standardized parameter estimates

accounts for 9.29\%. Besides, extracurricular activities play a significant complete mediating role in the relationship between Major and Professional skills, which accounts for $86.80 \%$ of the total effects. While, it plays a significant partial mediating role in the relationship between Major and Interpersonal skills, which accounts for $3.56 \%$. What's more, extracurricular activities have a significant complete mediating effect in the relationship between Gender and Professional skills, which accounts for $83.98 \%$. It also plays a significant complete mediating role in the relationship between Gender and Interpersonal skills, which accounts for $47.81 \%$. In the sample of non-normal $\mathbf{s}$ undergraduates, the model's standardized path parameters are shown in Fig.4. The extracurricular activities had a significant partial mediating effect in the relationship between Employment service and Professional skills, which devotes $61.71 \%$ of the total effect. It also has a significant complete mediating effect in the relationship between Professional service and Interpersonal skills, which devotes $15.85 \%$ of the total effect. And the significant partial effect of it in the relationship between Professional service and Information acquisition skills makes up $1.97 \%$. Further, extracurricular activities had a significant partial mediating effect in the relationship between Major and Professional skills, which devotes $62.86 \%$ of the total effect. It also plays a significant partial mediating role in the relationship between Major and Information acquisition skills, which devotes $3.68 \%$. Finally, extracurricular activities had a significant complete mediating effect in the relationship between Gender and Professional skills, which accounts for $80 \%$ of the total effect. It also plays a significant complete 
mediating role in the relationship between Gender and Interpersonal skills devoting $52.31 \%$ of the total effect, as well as that between Gender and Information acquisition skills accounts for $9.59 \%$. As we can see it, compared to normal colleges, the variable extracurricular activities in non-normal undergraduates has more stronger mediating effects in the relationships between other influencing factors and Employability. Accordingly, $\mathrm{H} 5$ and $\mathrm{H} 6$ have been confirmed. (Note: ${ }^{* * *} \mathrm{p}<0.01$, ${ }^{* *} \mathrm{p}<0.05,{ }^{*} \mathrm{p}<0.1$ in Fig.1-4)

\section{CONCLUSION AND LIMITATION}

In conclusion, firstly, the variables including Job intension, extracurricular activities and Employment service have a partly direct impact on Employability, respectively and significantly. If job seekers get too much professional service, they may spend less time studying professional skills, thus crippling their skills. However, more employment service contribute to undergraduates' higher interpersonal and information acquisition skills. Besides, having more extracurricular activities will be good to their professional and interpersonal skills. Second, the variables Job intension and extracurricular activities have significant mediating effects between other influencing factors and employability. Further these mediated effects are different in two groups - normal and non-normal universities: 1) In the normal universities sample, undergraduates' education has greater influence on their minds finding inner satisfied work compared to counterparts, thus indirectly influencing employability. 2) The mediating effects of extracurricular activities are stronger than those in normal colleges. This is attributed to differences in training objectives between two types of colleges. Compared with normal colleges, non-normal universities pay more attention to training interpersonal and information acquisition skills. 3) Art students are more likely to participate with social activities in normal universities, while science students tend to take part in extracurricular activities in non-normal universities. Combined with the second point, the mediating effects of extracurricular activities in normal art students are more significant than in other types of students. 4) The mediated effects in two groups of extracurricular activities to the relationships between Employability and Personal characteristics are more different than those of Job intension.

There are several limitations to this study. First, choosing only one university as the sample of normal ones in mainland China may not reflect this group's characteristics completely and exactly. Moreover, this article attempt to select indicators of employability fully and efficiently. However, there still exist subjectivity in the selection of some variables.

\section{REFERENCES}

[1] Chen Yong. The study on undergraduates' employability and its development path[D]. Zhejiang University, 2012. (In Chinese)

[2] J Hillage, E Pollard. Employability: Developing A Framework for Policy Analysis, ISBN 085522889 X [R]. Department for Education and Employment, 1998, January.

[3] Bennett N., Dunne E. and Carre' C., Patterns of core and generic skill provision in higher education [J]. Higher Education, 1999, 37, 71-93.
[4] Yorke, M. and Knight, P. Self-theories: some implications for teaching and learning in higher education[J]. Studies in Higher Education, 2004, 29 (1), 25-37.

[5] Lorraine Dacre Pool, Peter Sewell, "The key to employability: developing a practical model of graduate employability", Education + Training, 2007, 49, (4): 277 - 289.

[6] Ruth Bridgstock. The graduate attributes we've overlooked: enhancing graduate employability through career management skills[J].Higher Education Research \& Development, 2009, 28 (1): 31-44.

[7] Harvey, L. Defining and Measuring Employability [J]. Quality in Higher Education, 2001, 7(2): 97-109.

[8] Xu Xianguo. The analysis on employability's components and influencing factors[J]. Co-op Erative Economy \& Science, 2005, (05): 109-110. (In Chinese)

[9] Nurita Juhdi, Fatimah Pa'Wan, Noor Akmar Othman, Han ifah Moksin. Factors Influencing Internal And External Employability Of Employees. [J]Business and Economics Journal, (BEJ)Volume 2010: 1-10.

[10] David J. Finch Leah K. Hamilton Riley Baldwin Mark Zehner, "An exploratory study of factors affecting undergraduate employability", Education + Training, 2013, 55 (7): 681 - 704

[11] Erik Berntson, Magnus Sverke, Staffan Marklund. Predicting Perceived Employability: Human Capital or Labour Market Opportunities?[J]. Economic and Industrial Democracy, 2006, 27 (2): 223-244.

[12] Washington O. Effects of cognitive and experimental group therapy on self-efficacy and perceptions of employability of chemically dependent women. Issues in Mental Health Nursing, 1999, 20(3): 181-98.

[13] Zeng Li. The review on employability and its factors[J]. Manager' Journal, 2010, (24): 52-53.(In Chinese)

[14] Zhao Weiyan, Hou Rixia, Lei Ming. The relationship between professional commitment and career decision self-efficacy[J]. Chinese Mental Health Journal, 2014, 22(11): 1686-1688.(In Chinese)

[15] Zeng Xianhui, LuoBin, Gong Liming.The study on employment quality of normal colleges' students at the grassroots level-using Gannan Normal University as an example[J].Journal of Hubei Correspondence University, 2014, 27(06):39-40.(In Chinese)

[16] Wang Qingsheng, Wang Qikai, Liu Hong.The study on the characteristics of graduates with high employment competitiveness [J] Journal of Chongqing University, 2011, 17(06):151-154.(In Chinese)

[17] Zhuang Yu.The interaction between participating extracurricular activities and cultivating professional ability in normal students-based on 27 normal colleges in China[J]. Global Education, 2013, 42(06):96-106.(In Chinese)

[18] Yang Hongbo, Hu Ping, Shi Chencheng. The study on effect factors of undergraduates' employability: the mediating effects of job wishes[J]. China Journal of Health Psychology, 2017, 25(11):1708-1715.(In Chinese)

[19] Liu Qiaozhi, Analysis on the situations and effects factors of undergraduates' employability —using graduates in Zhejiang Province as an example[J].Study on China Youth, 2012(6):68-70.(In Chinese)

[20] Liu Hailing.The study on analysis and advice towards the effects of job wishes on employment-Based on undergraduates[J].Labor Security World, 2010(8): 14-17.(In Chinese)

[21] Eivis Qenani, Neal MacDougall, Carol Sexton. An empirical study of selfperceived employability: Improving the prospects for student employment success in an uncertain environment[J]. Active Learning in Higher Education, 2014, 15(3):199-213.

[22] Huang Yuqian, Liu Qin, Yang Qian, Zhang Jinfu. Self-esteem as the mediator of the relationships between general self-efficacy and employability among college students[J]. Journal of Psychology Research, 2014, 7(01): 91-96.(In Chinese)

[23] Wang Yan, Wang Wei, Lei Li. Job intension and employability of undergraduates: The mediator of career decision self-efficacy[J].Theory and Practice of Education, 2016, 36(09):9-11.(In Chinese)

[24] Ye Baojuan, Zheng Qing, Dong Shenghong, Fang Xiaoting, Liu Linlin.The effect of calling on employability of college students: the mediating role of job searching clarify and job searching self-efficacy[J].Psychological Development and Education, 2017, 33(01):37-44.(In Chinese) 
[25] Zhang Meng, Ma Liandi, Xue Mei, Liu Ping. The mediating effect of career exploring between self-efficacy and employability among nursing undergraduates[J]. Continuing Medical Education, 2016, 30(07): 68-71.(In Chinese)

[26] Liu Xuemei.The influence of undergraduates' career success values on their job intension.[J].Journal of Higher Education, 2013(5): 76-82.(In Chinese)

[27] Wen Zhonglin, Hou Kit-Tai, Chang Lei. The comparison and application on moderating effects and mediating effects.[J] Acta Psychologica Sinica, 2005, 37(2): 268-274.(In Chinese) 